Case report

\title{
Treatment of the newborn with a floating thrombus in the right atrium: case report
}

\author{
Ildar N. Nurmeev ${ }^{1}$, Artem A. Kostromin ${ }^{2}$, Bruce Okoye ${ }^{3}$ \\ ${ }^{1}$ Kazan Medical University, Kazan, Russia \\ ${ }^{2}$ Childrens Republican Hospital, Kazan, Russia \\ ${ }^{3}$ St Georges Hospital NHS Trust, London, United Kingdom
}

Received 27 May 2018, Revised 9 December 2018, Accepted 28 December 2018

(C) 2018, Nurmeev I.N., Kostromin A.A., Okoye B.

(C) 2018, Russian Open Medical Journal

Abstract: Venous thrombosis in newborns in pediatric surgery is rare. Aim of the article: description of the case of treatment of a newborn with a floating thrombus of the right atrium. This article reports the case of a 26 -day-old child with a floating right atrium thrombus with a background of late neonatal sepsis, septicemia, osteomyelitis of the proximal humerus, severe anemia and bacterial endocarditis. Primary cause of the right atrial thrombus was a complicated course of pregnancy with anemia, inflammatory disease and colpitis of the mother in the obstetric history. Features of presented case: surgical removal of thrombus with cardiopulmonary bypass.

Conclusion - Thrombosis of the heart cavities in newborns is a rare and dangerous condition, requiring urgent treatment. The presence of a floating thrombus in the heart cavity, is an indication for the surgical removal of a thrombus.

Keywords: children, newborn, floating, thrombus, heart, removal, treatment.

Cite as Nurmeev IN, Kostromin AA, Okoye B. Treatment of the newborn with a floating thrombus in the right atrium: case report. Russian Open Medical Journal 2019; 8: e0111.

Correspondence to Ildar N. Nurmeev. E-mail: nurmeev@gmail.com

\section{Introduction}

Despite the fact that deep vein thrombosis in adult patients is widespread, venous thrombosis in children is quite rare [1]. The main difference in etiopathogenesis between pediatric and adult venous thrombosis is the frequent association with central venous catheter usage in pediatric patients [2]. Currently, guidelines and recommendations are devoted to the prevention of catheterassociated thrombosis $[3,4]$. The main treatment modalities are anticoagulation and thrombolytic medication $[5,6]$. This article reports the case of a 26-day-old child with a floating right atrium thrombus.

Aim of the article: description of diagnosis and management of a newborn with a floating thrombus of the right atrium.

\section{Case report}

Child Z., was admitted at the age of 16 days to the Children's Hospital in Kazan city, with the diagnoses of: "sepsis, septicopyemia and abscesses of the upper and lower extremities". Medical history: Gravida 1, Para 1, gestational age 39.5 weeks. Obstetric and gynecological history: toxicosis gravidarum, colpitis, anemia. Vital data at birth: height $56 \mathrm{~cm}$, bodyweight $3,715 \mathrm{~g}$. Immediately after birth, the newborn had multiple abscesses of various sizes, located throughout the body of the child, predominantly on the limbs. The first surgery was performed at the regional hospital at the age of 14 days with drainage of the abscesses of the left wrist area, both forearms, left shoulder and left ankle area.

Blood tests on admission demonstrated anemia (hemoglobin $87 \mathrm{~g} / \mathrm{L})$, leukocytosis $\left(19.15 \times 10^{9} / \mathrm{L}\right)$ and elevated erythrocyte sedimentation rate (ESR) level $(22 \mathrm{~mm} / \mathrm{h})$. No significant abnormalities were detected in coagulogram: fibrinogen $3.5 \mathrm{~g} / \mathrm{L}$, prothrombin index $100.3 \%$, international normalised ratio (INR) 0.97 Unit, activated partial thromboplastin time (APTT) $49 \mathrm{~s}$, thrombin time $31.1 \mathrm{~s}$.

During the ongoing therapy, the results of blood tests showed increased level of hemoglobin to $157 \mathrm{~g} / \mathrm{L}$, a reduction in the level of ESR up to $21 \mathrm{~mm} / \mathrm{h}$ and leukocytes to $15.9 \times 10^{9} / \mathrm{L}$.

Echocardiogram revealed a thrombus of the cavity of the right atrium. The thrombus was in an hour glass form with two segments. The first, (size $7.6 \times 5.1 \mathrm{~mm}$ ) was fixed to the endocardium of the posterior wall of the right atrium just near the mouth of the inferior vena cava. The second (size $7.1 \times 8.5 \mathrm{~mm}$ ) prolapsed through the lumen of the tricuspid valve into the cavity of the right ventricle. Both elements of the thrombus were connected by a long movable stalk with a diameter of $1.7 \mathrm{~mm}$ (Figure 1).

A diagnosis of right atrial thrombus with a background of late neonatal sepsis, septicemia, osteomyelitis of the proximal humerus, severe anemia and bacterial endocarditis. The presence of a thrombus with flotation of one of its components was considered very high risk for non-surgical treatment or thrombolysis. A multi disciplinary decision involving pediatricians, cardiologists and surgeon was made to proceed to an open thrombectomy under cardiopulmonary bypass. The child had also been commenced on anticoagulant therapy with heparin sodium infusions at a dose of $30 \mathrm{U} / \mathrm{kg}$ per day. 


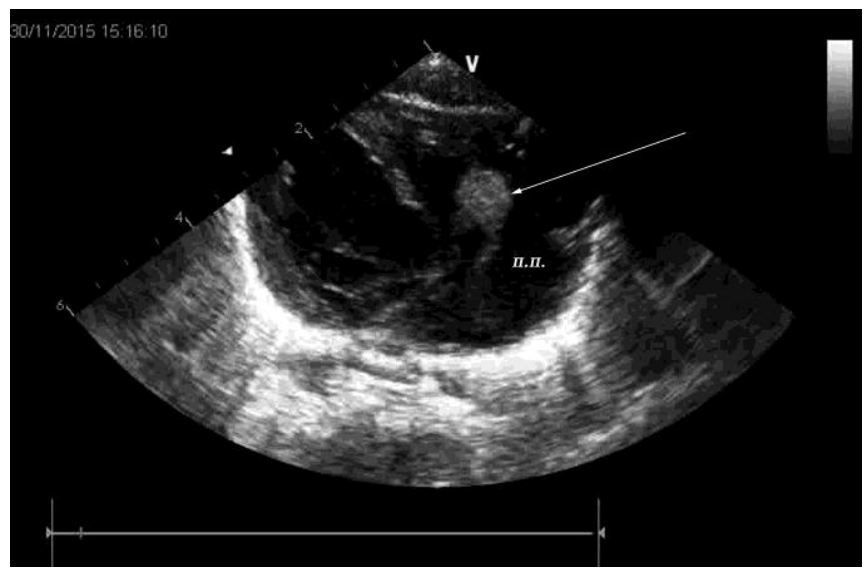

Figure 1. A thrombus of the cavity of the right auricle. The echogram. The thrombus is indicated by an arrow. П.П. - right atrium.

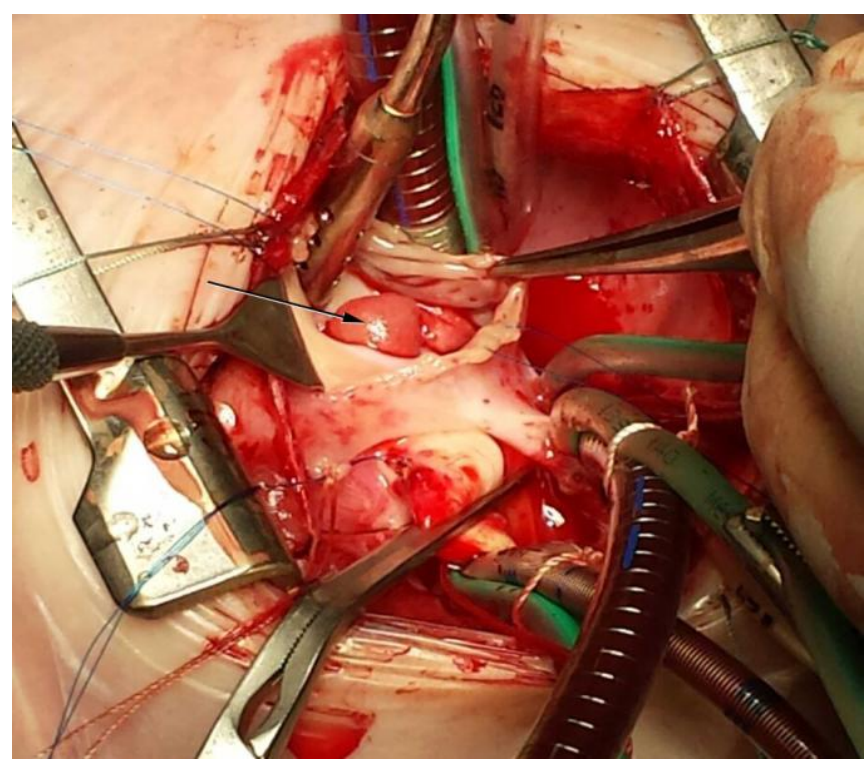

Figure 2. Thrombus of the right atrium. The bypass device is connected, right atrium cavity is opened.

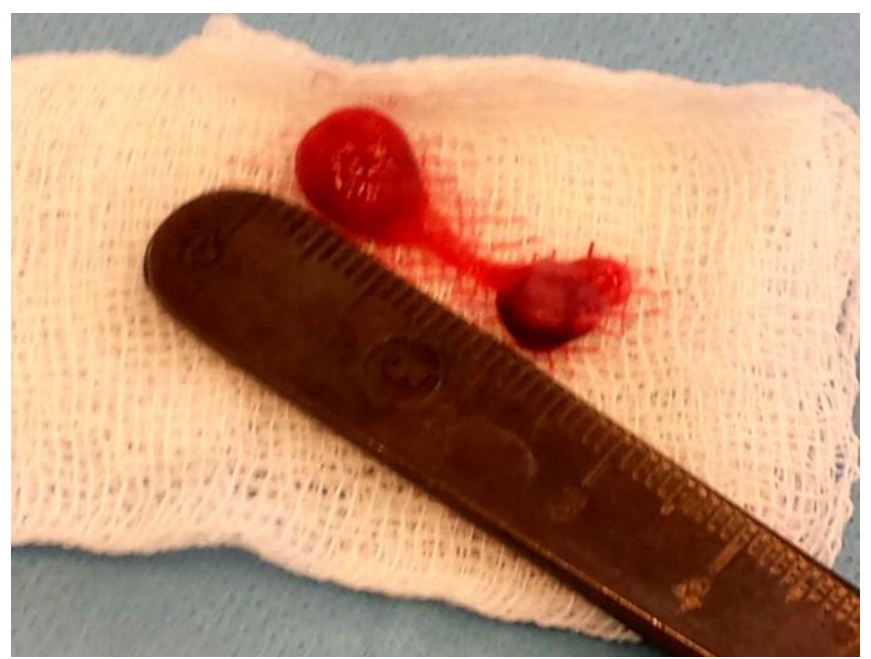

Figure 3. Thrombus of the right atrium.
The child underwent surgery on day 26 of life. The right atrium thrombus was removed under cardiopulmonary bypass. Surgical access was by longitudinal median sternotomy. For cardioplegia, a solution of Custodiol ${ }^{\circledR}$ was used. After cardiac arrest and opening of the right atrial cavity, a mobile thrombus $7 \times 8 \times 7 \mathrm{~mm}$ with a thin base with fixation near the mouth of the superior vena cava was detected, where the second part of the thrombus was located with dimensions $6 \times 5 \times 6 \mathrm{~mm}$ (Figure 2) The thrombus, as well as its base, were removed (Figure 3). Inspection of the tricuspid valve confirmed the absence of pathological changes in it. A standard disconnection of the bypass apparatus, renewal of the heart rhythm, drainage, and layer-by-layer closure of the thorax was performed. The total duration of the bypass was 46 minutes, including a cardiac arrest time 23 minutes.

Treatment in intensive care unit after the operation lasted 7 days. Assisted lung ventilation was needed for 97 hours. The child was treated with antibiotics: meropenem, vancomycin, and fluconazole. Cardiotonic medications were adrenaline and dopamine. Fentanyl was used for analgesia and heparin was used for anticoagulation.

A few days later, at the age of 1 month 5 days, a non-floating thrombus was detected around the right internal jugular central venous catheter (Figure 4). The central venous catheter was removed immediately, anticoagulant therapy was continued, followed by the replacement of heparin sodium with Nadroparine with a dose of $950 \mathrm{IU}$ per day (child's age was 1 month 10 days).

Blood tests before discharge of the child showed a normal level of hemoglobin $(148 \mathrm{~g} / \mathrm{L})$, leukocytes $\left(11.46 \times 10^{9} / \mathrm{L}\right)$ and ESR $(12 \mathrm{~mm} / \mathrm{h})$. At the age of 1 month 11 days the child was discharged with full recovery to continue anticoagulant therapy for 1 month followed by an ultrasound.

One month after discharge, the child was in a satisfactory condition with absence of cardiac and respiratory insufficiency. Anticoagulant therapy was stopped. Ultrasound of the central veins showed no thrombi. Echo of the heart cavities confirmed the absence of pathological formations in the heart. There were no recurrent thrombotic events and signs of postthrombotic syndrome.

\section{Discussion}

In our opinion, the primary cause of the right atrial thrombus was a complicated course of pregnancy with anemia, inflammatory disease and colpitis of the mother in the obstetric history. Purulent-inflammatory disease of the child, persistence of sepsis and the presence of a number of purulent foci were predisposing factors for the development of thrombotic complications.

Floating thrombus in the right atrium of a neonate with a successful outcome following treatment is very rare. Typically, open thrombus removal is required. However, a final cure was achieved with the combined use of surgical intervention, anticoagulant and antibiotic therapy. We have not identified similar cases of diagnosing of flotation thrombi in the heart cavity of a newborn, with successful treatment in the domestic and foreign medical literature.

This case illustrates the need for awareness of the possible development of venous thrombosis in newborns with sepsis. 


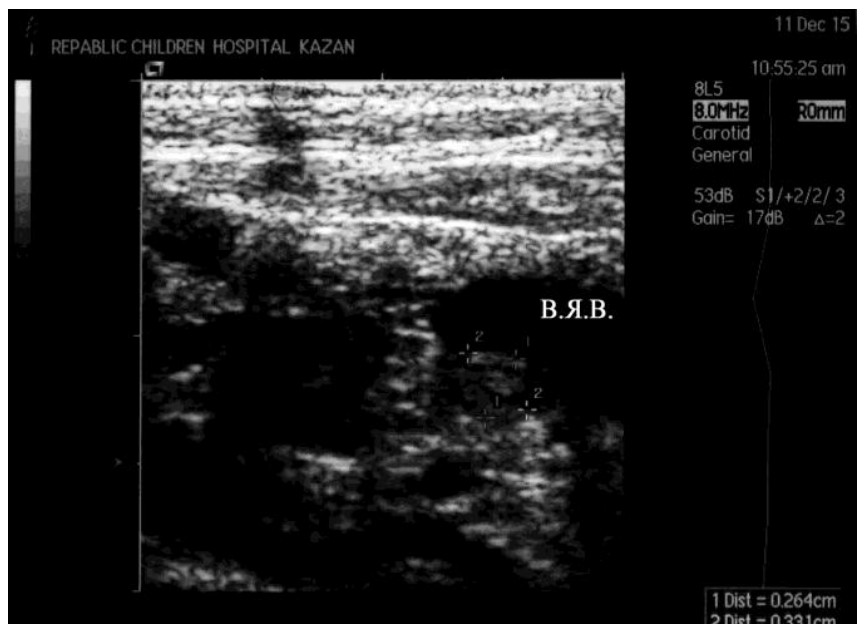

Figure 4. A thrombus in the lumen of the right internal jugular vein. The echogram. В.Я.В. - Internal jugular vein.

\section{Conclusion}

Thrombosis of the heart cavities in newborns is a rare and dangerous condition, requiring urgent treatment. The presence of a floating thrombus in the heart cavity is an indication for the surgical removal of a thrombus.

\section{Conflict of interest}

The authors declare that they have no conflict of interest.

\section{References}

1. Jung $\mathrm{H}$. Venous thromboembolism in children and adolescents. Blood Res 2016; 51(3): 149-151. https://dx.doi.org/10.5045/br.2016.51.3.149.

2. Nurmeev IN, Mirolyubov LM, Grebnev PN. Diagnostics and treatment of ileofemoral thrombosis in children. Russian Journal of Pediatric Surgery 2008; (1): 29-31. Russian. https://elibrary.ru/item.asp?id=23066729.

3. Shah PS, Shah VS. Continuous heparin infusion to prevent thrombosis and catheter occlusion in neonates with peripherally placed percutaneous central venous catheters. Cochrane Database Syst Rev 2008; 16(2): CD002772. https://doi.org/10.1002/14651858.CD002772.pub3.

4. Vidal E, Sharathkumar A, Glover J, Faustino EVS. Central venous catheter-related thrombosis and thromboprophylaxis in children: a systematic review and meta-analysis. J Thromb Haemost 2014; 12(7): 1096-1109. https://dx.doi.org/10.1111/jth.12598.

5. Monagle P, Chan AKC, Goldenberg NA, Ichord RN, Journeycake JM, NowakGöttl U, et al. Antithrombotic therapy in neonates and children. Chest 2012; 141(2, Suppl): e737S-e801S. https://dx.doi.org/10.1378/chest.11$\underline{2308}$.

6. Greene LA, Goldenberg NA. Deep vein thrombosis: thrombolysis in the pediatric population. Semin Intervent Radiol 2012; 29(1): 36-43. https://dx.doi.org/10.1055/s-0032-1302450.

\section{Authors:}

Ildar N. Nurmeev - MD, DSc, Professor, Department of Pediatric Surgery, Kazan Medical University, Kazan, Russia. http://orcid.org/0000-0002-10231158.

Artem A. Kostromin - MD, Pediatric Cardiac Surgeon, Department of Cardiovascular Surgery, Childrens Republican Hospital, Kazan, Russia. https://orcid.org/0000-0002-8215-4219.

Bruce Okoye - FRCS (Eng), FRCS (Paed), MD, Department of Paediatric Surgery, St Georges Hospital NHS Trust, London, United Kingdom. http://orcid.org/0000-0003-0255-6638. 